\title{
Enhancement in Thermal Stability of Polyoxymethylene (POM)-Based Biopolymer Blend Materials
}

\author{
Jitlada Boonlertsamut ${ }^{*}$, Supaphorn Thumsorn², Toshikazu Umemura3 ${ }^{3}$, Hiroyuki Hamada1, \\ Atsushi Sakuma ${ }^{1}$
}

${ }^{1}$ Department of Advanced Fibro-Science, Kyoto Institute of Technology, Kyoto, Japan

${ }^{2}$ Department of Industrial Engineering, Pathumwan Institute of Technology, Bangkok, Thailand

${ }^{3}$ Plaisir Co., LTD., Osaka, Japan

Email: *b.jitladaa@gmail.com

How to cite this paper: Boonlertsamut, J., Thumsorn, S., Umemura, T., Hamada, H. and Sakuma, A. (2019) Enhancement in Thermal Stability of Polyoxymethylene (POM)-Based Biopolymer Blend Materials. Journal of Materials Science and Chemical Engineering, 7, 67-78.

https://doi.org/10.4236/msce.2019.77008

Received: May 29, 2019

Accepted: July 20, 2019

Published: July 23, 2019

Copyright $\odot 2019$ by author(s) and Scientific Research Publishing Inc. This work is licensed under the Creative Commons Attribution International License (CC BY 4.0).

http://creativecommons.org/licenses/by/4.0/

\begin{abstract}
In this study, we demonstrate the enhancement in thermal stability of polyoxymethylene (POM)-based biopolymer blend materials. Polyoxymethylene (POM)/Polylactic acid (PLA) blends have been used as alternative biopolymer materials for supporting environmental problems with thermal stability feature. The effects on POM biopolymer blend materials with a controlled PLA amount in their compositions under various injection conditions, were investigated by thermogravimetric analysis, dynamic mechanical analysis, and differential scanning calorimetry. The POM/PLA biopolymer blend materials showed POM phase acted as a homogeneous nucleating site for increasing PLA crystallization, which improves storage modulus of the blend materials. The decomposition temperatures of POM/PLA biopolymer blends tend to shift around $30^{\circ} \mathrm{C}-50^{\circ} \mathrm{C}$ lower compared to the decomposition temperatures of PLA. Thus, the decomposition temperature behavior of POM/PLA blends seems to be closer to POM. The suitable ratio in POM70/PLA30 resulted in the high strength of the blend materials. The POM/PLA biopolymer blend material was tested at various injection speeds and good miscibility was obtained at an injection speed of $100 \mathrm{~mm} / \mathrm{s}$. This enhancement of thermal stability in POM/PLA blend materials should be useful in the development of high-performance bio-based thermoplastic materials.
\end{abstract}

\section{Keywords}

Polyoxymethylene, Poly (Lactic Acid), Biopolymer, Injection Speeds 


\section{Introduction}

This research focuses on the enhancement in thermal stability of POM biopolymer blend materials with controlled components in the compositions under varied injection conditions, where polyoxymethylene (POM) is selected as the main material. The engineering industry requires materials with high strength and durability, which does deform easily, among other properties. POM is a semi-crystalline engineering thermoplastic that has reported high stiffness, toughness, thermal, and dimensional stability [1] [2] [3]. To overcome the disadvantages of polymers, blending different polymers is nominated as a convenient way to develop alternative polymeric materials. The polymer blend may have intermediate properties between those of the individual components. However, miscibility is unusual in polymer blends, considering the complexities of the components in the compositions. Many researchers have reported using specific contents of some components with great care to obtain the required combination [4] [5]. Miscibility is a favorable feature because it is usually associated with a good level of mechanical properties. Thus, it is interesting to study the individual component behaviors and mechanical and thermal properties of either miscible or partially miscible polymer blends.

Nowadays, biopolymers have become the most popular material for supporting environmental problems. The thermoplastic compositions are required to be based on potentially renewable raw materials, at least in part. Polylactic acid (PLA) is classified as a biopolymer-based material and has advantageous properties such as high stiffness and strength but suffers from brittleness and low toughness [6] [7] [8]. It is possible to adjust POM-based blend materials by using properties of PLA content to get the desired performance. The appropriate composition of PLA can produce bio-based polymer blend materials. The documented resources show that PLA has limitations in its applications due to its low glass transition temperature $\left(\mathrm{T}_{\mathrm{g}}\right)$ [9] [10]. At temperatures higher than $56^{\circ} \mathrm{C}$ as the $\mathrm{T}_{\mathrm{g}}$ of PLA [11], only the crystalline phase of PLA can offer excellent mechanical and thermal properties. Therefore, the crystalline form is important as it increases the temperature resistance and thermal stability of the material. The highest degree of crystallinity in the total crystallization was reported to be approximately $40 \mathrm{wt} \%$ PLA [12]. Considering the fabrication process of the blend materials, it is well known that the process conditions affect the polymer characteristics and properties. The injection speed is one such process condition that was considered for improving the polymer structure after careful speed adjustment. If the injection speed exceeds a certain limit, the materials reach a high temperature that may lead to a change in its molecular orientation as well as characteristics [13] [14].

In this work, the designation of the compositions for the controllable thermal stability of PLA in the POM/PLA blends and the effects of injection speeds on the thermal properties were evaluated. 


\section{Experimental}

\subsection{Materials}

Mitsubishi Engineering-Plastic Co., Ltd. from Japan supplied the POM as copolymer under the trade name Lupital V20-HE. PLA (biopolymer) was supplied by Unitika Ltd. from Japan under the trade name TERRAMAC TE-2000. The blending technique was used in this study. The melting temperatures of POM and PLA are $155^{\circ} \mathrm{C}$ and $170^{\circ} \mathrm{C}$, respectively. The densities of POM and PLA are $1.39 \mathrm{~g} / \mathrm{cm}^{3}$ and $1.25 \mathrm{~g} / \mathrm{cm}^{3}$, respectively, as per ISO 1183 . The melt flow rates of POM and PLA are $10 \mathrm{~g} / 10 \mathrm{~min}$ at a temperature of $190^{\circ} \mathrm{C}$ and a load of $2.16 \mathrm{~kg}$, according to ISO 1133.

\subsection{Preparation of Specimens}

POM-based and PLA biopolymer pellets were dried in an oven at $80^{\circ} \mathrm{C}$ for $16 \mathrm{~h}$ to remove all moisture. Next, all pellets were blended using a dry blending method. The compositions of POM/PLA blends are determined in Table 1. The dumbbell shaped specimens were fabricated using an injection molding machine (PO YUEN UM50) as shown in Figure 1. The injection speeds used were 10 $\mathrm{mm} / \mathrm{s}, 50 \mathrm{~mm} / \mathrm{s}, 100 \mathrm{~mm} / \mathrm{s}$, and $1000 \mathrm{~mm} / \mathrm{s}$. The barrel temperatures from the hopper to the nozzle were adjusted to $160^{\circ} \mathrm{C}, 160^{\circ} \mathrm{C}, 180^{\circ} \mathrm{C}, 190^{\circ} \mathrm{C}$, and $190^{\circ} \mathrm{C}$. The mold temperature and cooling time were set at $30^{\circ} \mathrm{C}$ and $20 \mathrm{~s}$, respectively.

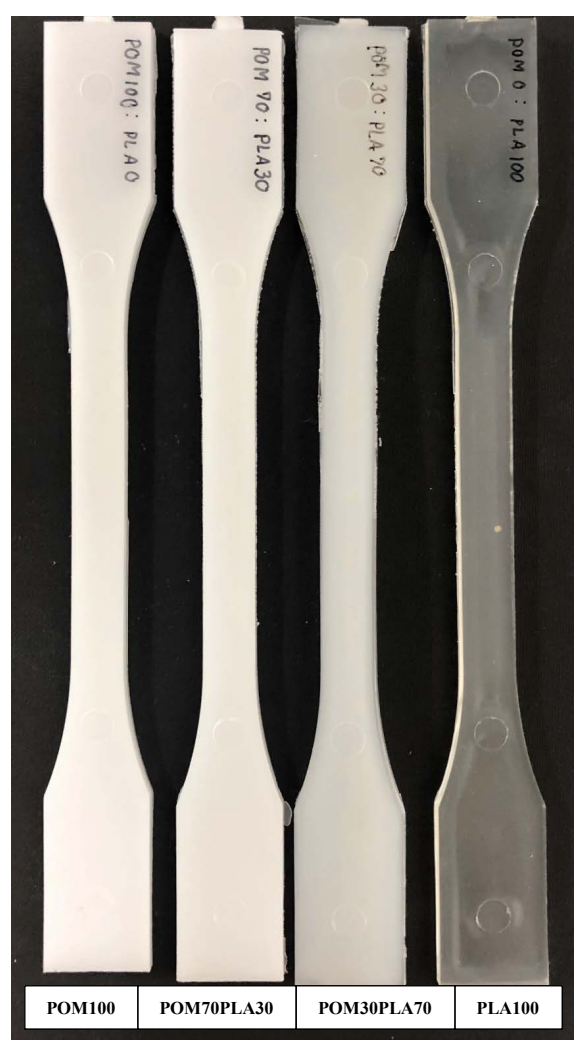

Figure 1. Photographs of dumbbell shaped specimens of POM, PLA, and their blends. 
Table 1. Summary of the specimen compositions of POM/PLA blends and labeling.

\begin{tabular}{ccc}
\hline Code & POM content $(w t \%)$ & PLA content $(w t \%)$ \\
\hline POM100 & 100 & 0 \\
POM70/PLA30 & 70 & 30 \\
POM30/PLA70 & 30 & 70 \\
PLA100 & 0 & 100 \\
\hline
\end{tabular}

\subsection{Test Procedures}

Differential scanning calorimetry, (DSC2920) from TA Instruments, can be defined as a technique to analyze the thermal properties of polymers. Specimens with weights between 5 - $10 \mathrm{mg}$ were cut from the biopolymer blend materials and put into aluminum pans. The ramp type DSC testing method was used. The specimens were heated from $25^{\circ} \mathrm{C}$ to $200^{\circ} \mathrm{C}$ at a heating rate of $10^{\circ} \mathrm{C} / \mathrm{min}$. The degree of crystallinity $\left(X_{c}\right)$ of the specimens was calculated by the following Equation (1):

$$
X_{c}=\frac{\Delta H_{m}}{\Delta H_{f 100} \times W_{P}} \times 100 \%
$$

where $\Delta H_{m}$ is the enthalpy of melting, $\Delta H_{f 100}$ corresponds to the heat of fusion at $100 \%$ polymer crystallization $\left(\Delta H_{f 100}\right.$ of POM and PLA is approximately 326 [15] and $93.6[16] \mathrm{J} / \mathrm{g}$, respectively), and $W_{P}$ is the net weight fraction of the polymer.

Dynamic mechanical analysis (DMA) is a technique that monitors the elastic and viscous response of a specimen under an oscillating load against time, temperature, or frequency of oscillation [17]. DMA was performed using DMA 2980 from TA Instruments that was assembled in a double-cantilever mode. The thickness, width, and length of the specimens were $3 \mathrm{~mm}, 10 \mathrm{~mm}$, and $60 \mathrm{~mm}$, respectively. The span length was set at $48 \mathrm{~mm}$. The DMA was carried out for variant oscillation frequencies of $0.1 \mathrm{~Hz}, 0.16 \mathrm{~Hz}, 0.25 \mathrm{~Hz}, 0.4 \mathrm{~Hz}, 0.63 \mathrm{~Hz}, 1 \mathrm{~Hz}$, $1.6 \mathrm{~Hz}, 2.5 \mathrm{~Hz}, 3 \mathrm{~Hz}, 6.3 \mathrm{~Hz}, 10 \mathrm{~Hz}, 15.8 \mathrm{~Hz}, 25 \mathrm{~Hz}, 39.8 \mathrm{~Hz}, 63 \mathrm{~Hz}$, and $100 \mathrm{~Hz}$ in the temperature range between $30^{\circ} \mathrm{C}$ to $100^{\circ} \mathrm{C}$ with an incremental temperature of $5^{\circ} \mathrm{C}$ for all specimens. In this study, storage modulus $(E)$, loss modulus $\left(E^{\prime}\right)$, and tan delta were reported as functions of temperature.

Thermogravimetric analysis (TGA) proceeded on the Discovery TGA equipment using TRIOS software (TA Instruments). Each specimen weighing approximately $2-5 \mathrm{mg}$ was cut from the biopolymer blend materials and put in a platinum-HT pan. The specimens were heated from $25^{\circ} \mathrm{C}$ to $600^{\circ} \mathrm{C}$ at a heating rate of $20^{\circ} \mathrm{C} / \mathrm{min}$ under nitrogen atmosphere.

\section{Results and Discussion}

\subsection{Effect of Injection Speeds on the Melting Temperature and Degree of Polymer Crystallinity of POM70/PLA30}

As mentioned before, the thermal properties of the blend materials can be im- 
proved by adding PLA content. However, the complexities of the components in the compositions are concerning. Specific content from some components has to be used carefully [18]. It is necessary to increase the amount of the crystalline form of the material in order to increase the temperature resistance. The maximum degree of crystallinity that can be obtained in the fully crystallized state is $40 \mathrm{wt} \%$ PLA [19]. Namely, to overcome the weakness in thermal properties of the POM/PLA blends, POM70/PLA30 seems to be a significantly high-performance material due to its suitable composition. Next, the effect of various injection speeds on POM70/PLA30 was investigated.

Figure 2 shows the DSC curves of POM70/PLA30 with various injection speeds, $10 \mathrm{~mm} / \mathrm{s}, 50 \mathrm{~mm} / \mathrm{s}, 100 \mathrm{~mm} / \mathrm{s}$, and $1000 \mathrm{~mm} / \mathrm{s}$. The DSC results of POM70/PLA30 were investigated by using the ramp method from room temperature $\left(25^{\circ} \mathrm{C}\right)$ to $200^{\circ} \mathrm{C}$. The melting temperatures $\left(\mathrm{T}_{\mathrm{m}}\right)$ of the POM phase of POM70/PLA30 are approximately $154.12^{\circ} \mathrm{C}, 154.08^{\circ} \mathrm{C}, 153.02^{\circ} \mathrm{C}$, and $154.02^{\circ} \mathrm{C}$ for injection speeds of $10 \mathrm{~mm} / \mathrm{s}, 50 \mathrm{~mm} / \mathrm{s}, 100 \mathrm{~mm} / \mathrm{s}$, and $1000 \mathrm{~mm} / \mathrm{s}$, respectively. While the $\mathrm{T}_{\mathrm{m}}$ values of the PLA phase of POM70/PLA30 are approximately $165.47^{\circ} \mathrm{C}, 165.59^{\circ} \mathrm{C}, 165.52^{\circ} \mathrm{C}$, and $165.82^{\circ} \mathrm{C}$ for injection speeds of 10 $\mathrm{mm} / \mathrm{s}, 50 \mathrm{~mm} / \mathrm{s}, 100 \mathrm{~mm} / \mathrm{s}$, and $1000 \mathrm{~mm} / \mathrm{s}$, respectively. These results indicate that the PLA content in POM70/PLA30 has no effect on the shifting of the Tm peaks of the blend materials. It can be considered that the results remain unchanged for the melting temperature of the materials in terms of thermal stability when using them in the industrial process.

Figure 3 shows the degree of crystallinity $\left(X_{c}\right)$ for POM70/PLA30 at various injection speeds, $10 \mathrm{~mm} / \mathrm{s}, 50 \mathrm{~mm} / \mathrm{s}, 100 \mathrm{~mm} / \mathrm{s}$, and $1000 \mathrm{~mm} / \mathrm{s}$. The results show that the in $X_{c}$ of polymer blends is significantly affected by the various injection speeds. Figure 5 illustrates the $X_{c}$ of POM70/PLA30 at various injection speeds, $10 \mathrm{~mm} / \mathrm{s}, 50 \mathrm{~mm} / \mathrm{s}, 100 \mathrm{~mm} / \mathrm{s}$, and $1000 \mathrm{~mm} / \mathrm{s}$. Moreover, next, the effect of change in $X_{c}$ on the polymer structure was considered. This behavior was investigated from the corresponding melting behaviors of the POM phase with

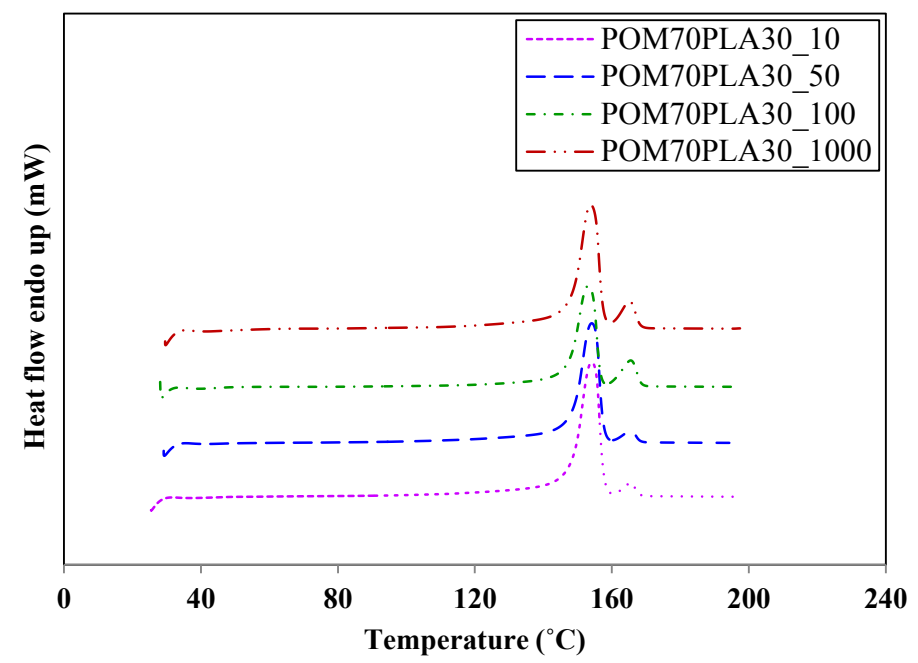

Figure 2. DSC curves of POM70/PLA30 with various injection speeds. 


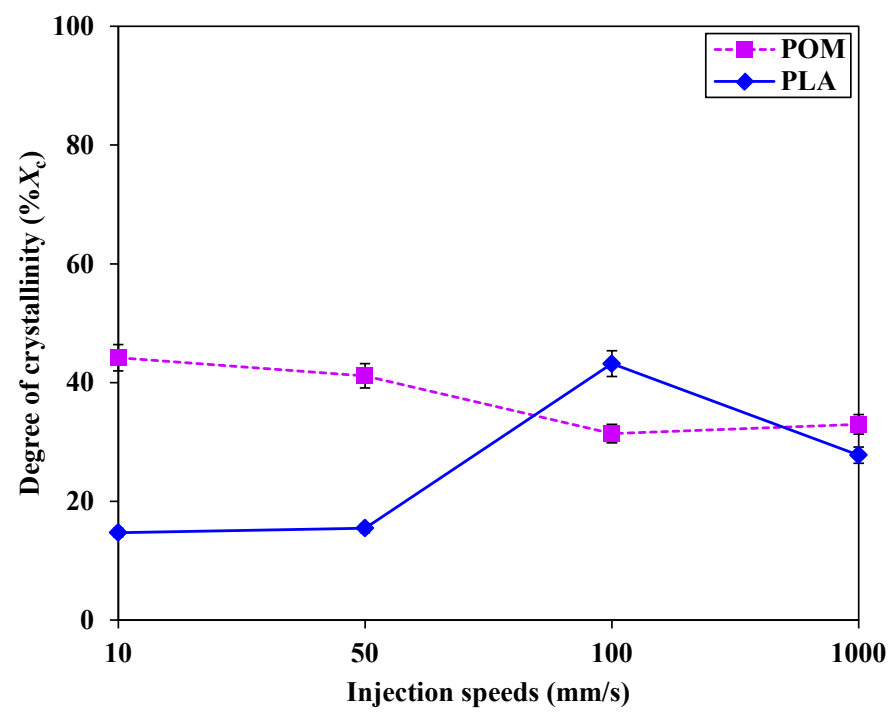

Figure 3. Degree of crystallinity $\left(X_{c}\right)$ of POM70/PLA30 with various injection speeds.

the PLA phase in POM70/PLA30. It was noted from the results that homogeneous crystallization in the way of partial miscibility of POM70/PLA30 was obtained at the injection speed of $100 \mathrm{~mm} / \mathrm{s}$. Hence, the results of change in $X_{c}$ of the POM phase show a small decrease with that with itself at the injection speed of $100 \mathrm{~mm} / \mathrm{s}$. Further, the $X_{c}$ result of the PLA phase shows a small increase with that with itself at the injection speed of $100 \mathrm{~mm} / \mathrm{s}$. It can be assumed that this behavior of the POM and PLA phase in POM70/PLA30 is seen at the injection speed of $100 \mathrm{~mm} / \mathrm{s}$ and leads to change in the polymer structure of polymer blends. Moreover, the good combination in the blend was also considered with the injection speed of $100 \mathrm{~mm} / \mathrm{s}$. In contrast, the $X_{c}$ results at other injection speeds do not strongly affect the polymer structure in the blend, considering the change in crystallinity.

\subsection{Effect of Content and Injection Speed on the Dynamic Mechanical Thermal Property}

Figure 4 demonstrates the dynamic mechanical thermal property of the blends and shows that it is related to the composition of the blend. In general, the property of good elasticity and good durability can be obtained in materials with high storage modulus. From the observation, the variation of DMA results of POM, PLA, and their blends were investigated at temperature between $30^{\circ} \mathrm{C}$ to $100^{\circ} \mathrm{C}$ at different frequencies (multi-frequency). The results indicated that each specimen showed the highest storage modulus for PLA and lowest for POM. For each specimen in the frequency sweep mode, the storage modulus increase is only marginal from the lower frequency to the higher frequency along the temperature step. It is clear that the storage modulus of POM, PLA, and their blends decrease with increasing temperature. At any given temperature, the storage modulus increases with increase in PLA content of the blend materials. The ad- 
dition of $70 \mathrm{wt} \%$ of POM contents yielded a higher degree of blended PLA crystallinity. It was attributed to the assumption that the POM phase acted as a homogeneous nucleating site for increasing PLA crystallization, which improves the storage modulus of the blend materials. Therefore, the PLA content in the blend has been used to improve the dynamic mechanical and thermal properties of the blend materials.

As reported previously, more polymers in the material compositions of each specimen have an active role in increasing the storage modulus of polymer blends [20] [21]. Figure 5 shows the storage modulus value of POM70/PLA30 at a frequency of $100 \mathrm{~Hz}$ with various injection speeds, $10 \mathrm{~mm} / \mathrm{s}, 50 \mathrm{~mm} / \mathrm{s}, 100$ $\mathrm{mm} / \mathrm{s}$, and $1000 \mathrm{~mm} / \mathrm{s}$. Note that the storage modulus at the injection speed of $10 \mathrm{~mm} / \mathrm{s}$ and $50 \mathrm{~mm} / \mathrm{s}$ only show a marginal increase, while the highest value of the storage modulus has occurred at the injection speed of $100 \mathrm{~mm} / \mathrm{s}$. However, when injection speed increases to $1000 \mathrm{~mm} / \mathrm{s}$, the value of storage modulus drops compared with the value of storage modulus at the previous injection speed.
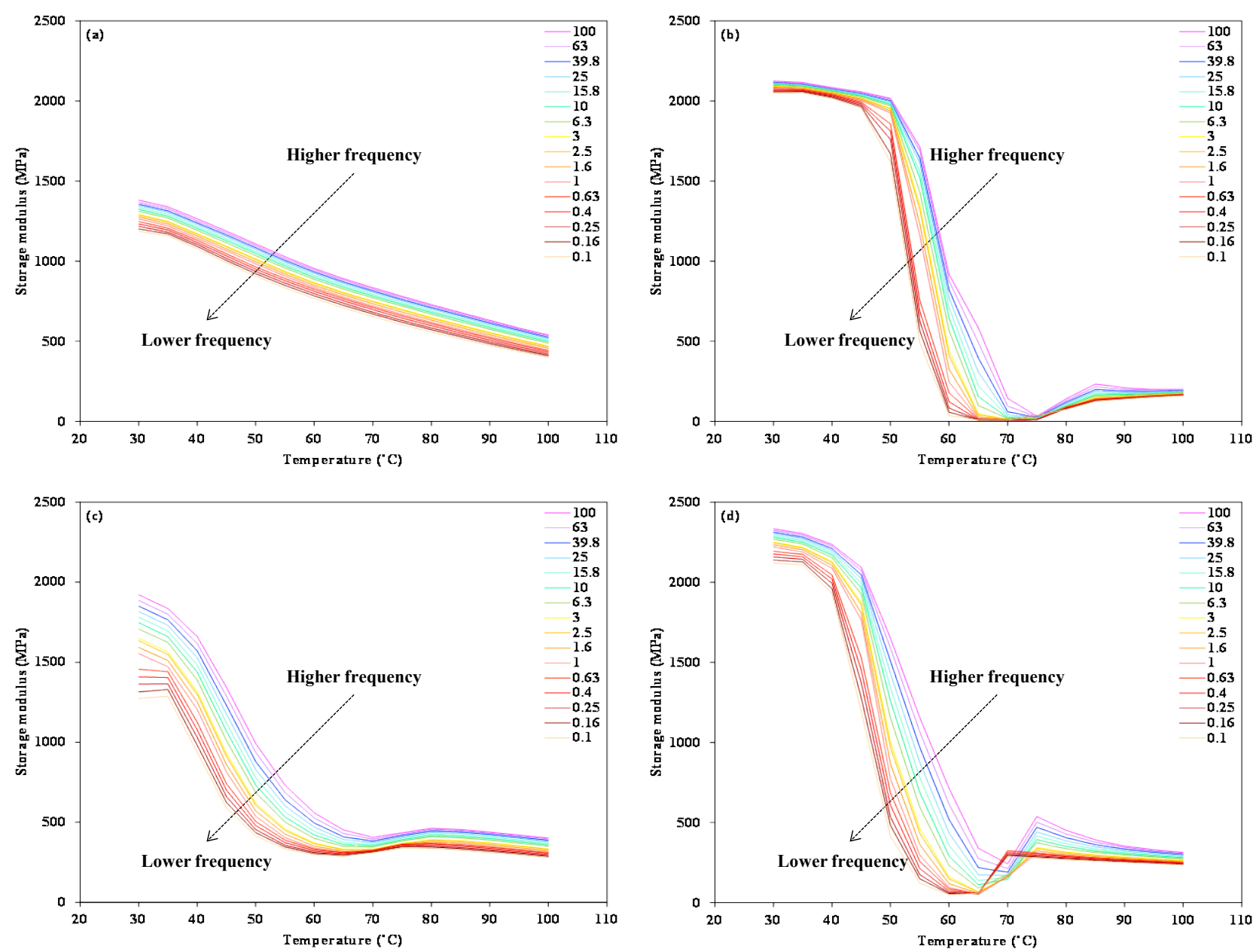

Figure 4. Storage modulus curves of polymer blends with different frequencies at the injection speed of $100 \mathrm{~mm} / \mathrm{s}$ for (a) POM100, (b) PLA100, (c) POM70/PLA30, and (d) POM30/PLA70. 


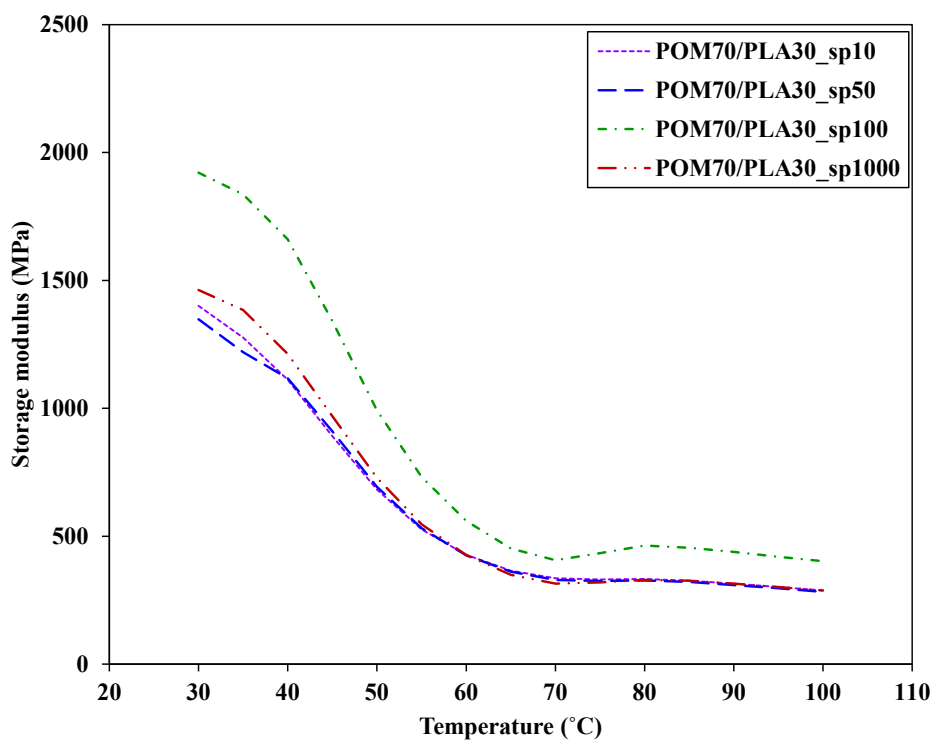

Figure 5. Storage modulus curves of POM70/PLA30 at a frequency of $100 \mathrm{~Hz}$ with various injection speeds of $10,50,100$, and $1000 \mathrm{~mm} / \mathrm{s}$.

Next, the mechanical properties compared to the temperature dependence were studied. The Loss modulus curves of POM70/PLA30 at different frequencies with various injection speeds are exhibited in Figure 6. It was found that the loss modulus of POM70/PLA30 increased with increase in the injection speed from $10 \mathrm{~mm} / \mathrm{s}$ to $100 \mathrm{~mm} / \mathrm{s}$ and then decreased when the injection speed was further increased to $1000 \mathrm{~mm} / \mathrm{s}$. The result indicates that the loss modulus of each specimen showed the highest value at the injection speed of $100 \mathrm{~mm} / \mathrm{s}$ in POM70/PLA30. However, it was observed that the material deforms easily with high loss modulus.

Figure 7 demonstrates the tan delta curves of POM70/PLA30 at different frequencies with various injection speeds. Generally, high strength material was obtained from the low tan delta curve. From the results, it was found that the blend materials becomes softer when the injection speed increases from $10 \mathrm{~mm} / \mathrm{s}$ to $100 \mathrm{~mm} / \mathrm{s}$ while it hardens again at the injection speed of $1000 \mathrm{~mm} / \mathrm{s}$. Furthermore, it was observed that the tan delta was related to storage modulus and loss modulus. Thus, it can be concluded that the official high strength material in the blend was specified as POM70/PLA30 at the injection speed of $100 \mathrm{~mm} / \mathrm{s}$.

\subsection{Effect of Content on the Thermal Stability and Decomposition Results in Thermogravimetric Analysis}

Figure 8 shows the TGA curves of POM, PLA, and their blends. The thermal stability and decomposition were estimated by measuring the sample weight along the time with change in the temperature [22]. For each specimen, the weight loss at the onset point up to $300^{\circ} \mathrm{C}$ was ascribed to humid volatilization of the specimen. The decomposition onset temperatures in the blend under the nitrogen atmosphere were approximately $328.88^{\circ} \mathrm{C}, 336.90^{\circ} \mathrm{C}, 340.58^{\circ} \mathrm{C}$, and 
$357.27^{\circ} \mathrm{C}$ for POM100, POM70/PLA30, POM30/PLA70, and PLA100, respectively. The decomposition temperatures of POM and their blends tend to shift around $30^{\circ} \mathrm{C}-50^{\circ} \mathrm{C}$ lower compared to the decomposition temperatures of PLA. Thus, it can be noted that the decomposition temperature behavior of POM/PLA blends seems to be closer to POM. However, shifting at a higher temperature in the blend could be seen in POM70/PLA30. The thermal stability of their blends shows a small increase with increasing PLA in the blend.

\section{Conclusion}

In this research, the complexities of components in the compositions of blend materials on the thermal stability controls were investigated, in addition the influence of various injection speeds on the thermal properties of POM/PLA blends is reported. From the results, it can be concluded that the appropriate ratio was determined to be POM70/PLA30 because it can improve the mechanical properties under temperature dependence when compared to the normal properties of POM and PLA. This research revealed that the POM phase acted as
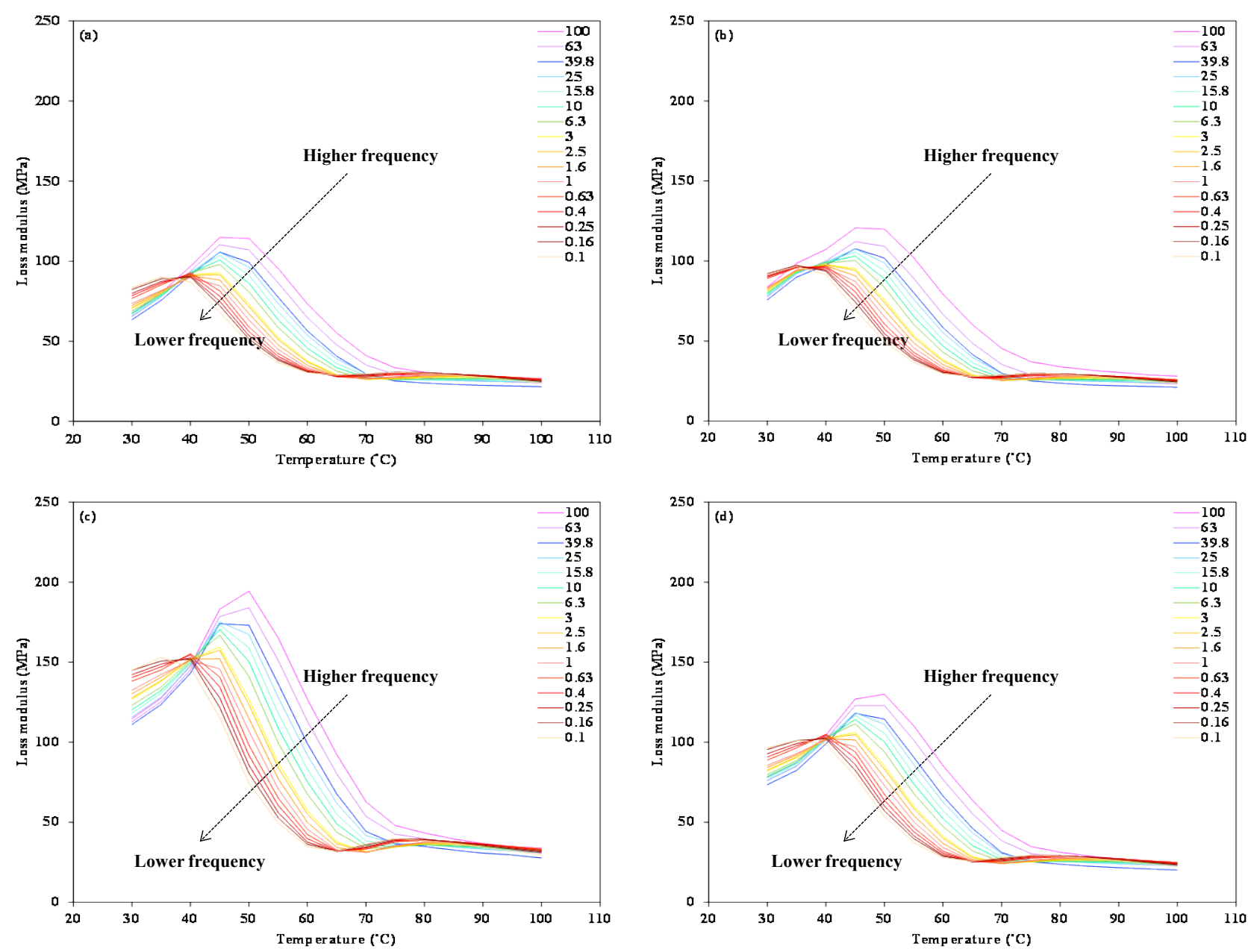

Figure 6. Loss modulus curves of POM70/PLA30 at different frequencies with various injection speeds of; (a) $10 \mathrm{~mm} / \mathrm{s}$, (b) 50 $\mathrm{mm} / \mathrm{s}$, (c) $100 \mathrm{~mm} / \mathrm{s}$, and (d) $1000 \mathrm{~mm} / \mathrm{s}$. 

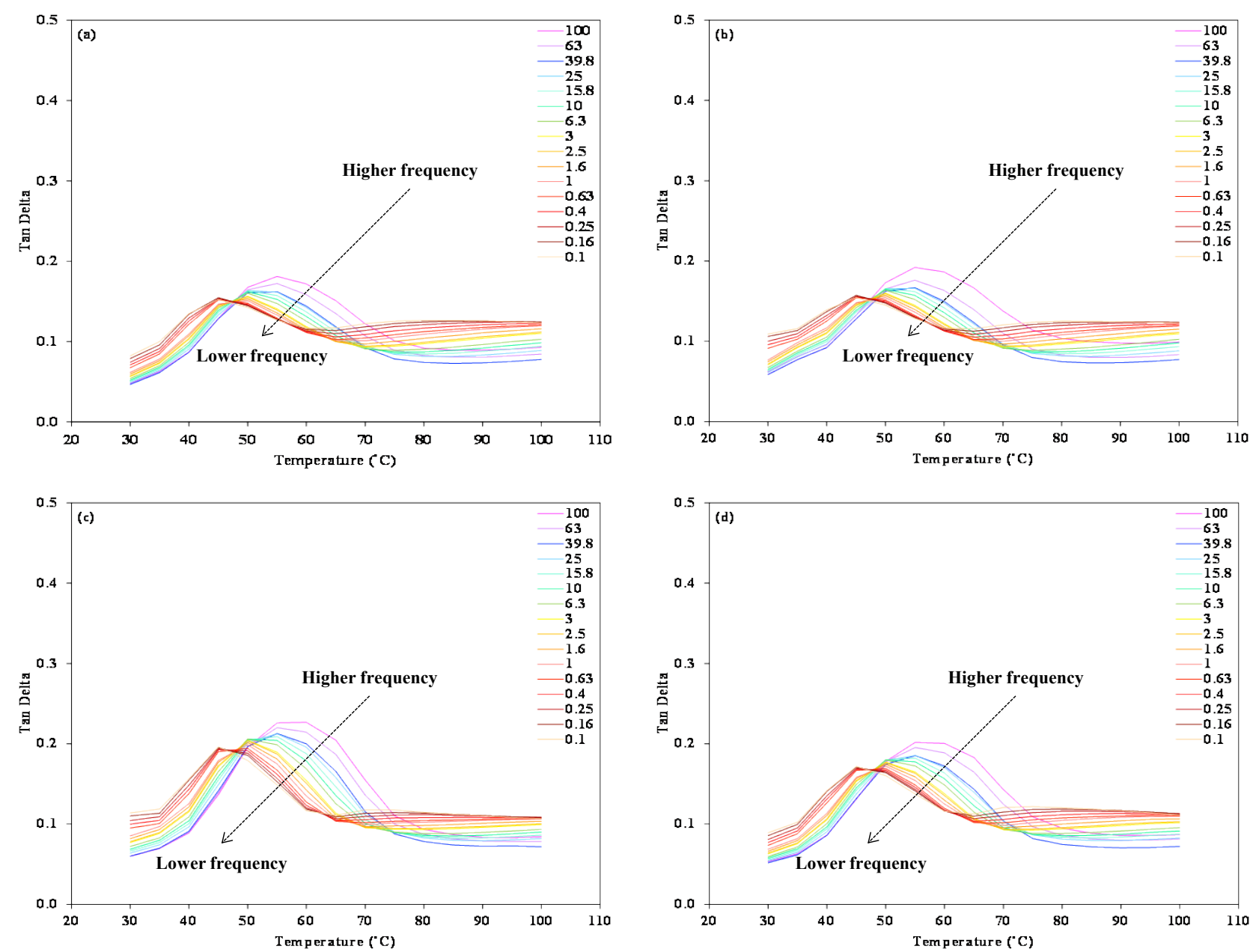

Figure 7. Tan delta curves of POM70/PLA30 at different frequencies with various injection speeds of; (a) $10 \mathrm{~mm} / \mathrm{s},(\mathrm{b}) 50 \mathrm{~mm} / \mathrm{s}$, (c) $100 \mathrm{~mm} / \mathrm{s}$, and (d) $1000 \mathrm{~mm} / \mathrm{s}$.

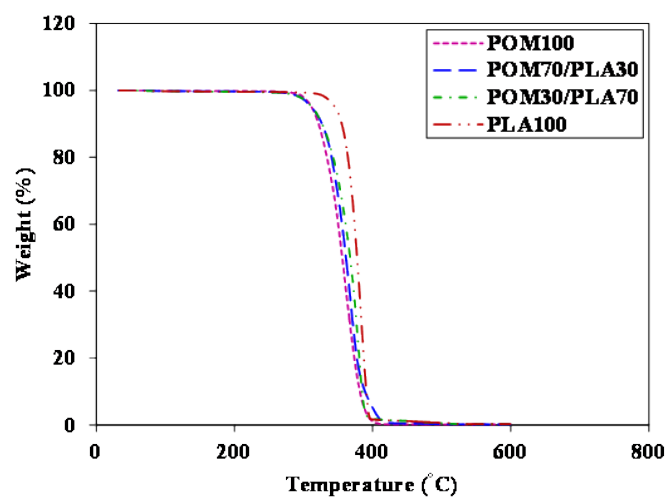

Figure 8. TGA curves of POM, PLA, and their blends at the injection speed of $100 \mathrm{~mm} / \mathrm{s}$.

a homogeneous nucleating site for increasing PLA crystallization, which improves storage modulus of the blend materials. Furthermore, considering the effect of various injection speeds, miscibility was obtained at an injection speed of $100 \mathrm{~mm} / \mathrm{s}$ because the crystallinity of POM and PLA phase was demonstrated by 
the degree of crystallinity at an injection speed of $100 \mathrm{~mm} / \mathrm{s}$. It was observed that a suitable composition of the blend could increase the dynamic mechanical and thermal properties, whereas, POM70/PLA30 with an injection speed of $100 \mathrm{~mm} / \mathrm{s}$ could slightly improve the decomposition temperatures.

\section{Conflicts of Interest}

The authors declare no conflicts of interest regarding the publication of this paper.

\section{References}

[1] Weissermel, K., Fischer, E., Gutweiler, K., Hermann, H.D. and Cherdron, H. (1967) Polymerization of Trioxane. Angewandte Chemie International Edition in English, 6, 526-533. https://doi.org/10.1002/anie.196705261

[2] Kern, W. and Jaacks, V. (2003) Some Kinetic Effects in the Polymerization of 1,3,5-Trioxane. Journal of Polymer Science, 48, 399-404. https://doi.org/10.1002/pol.1960.1204815040

[3] Chernie, D.M. (1968) A Method of Determining the Active Centers in Catioiiic Polymerization. Applied to Polymerization of Dioxolane, Trioxane, and Formaldehyde, 118, 354-360.

[4] Wu, J., Schultz, J.M., Samon, J.M., Pangelinan, A.B. and Chuah, H.H. (2002) In Situ Study of Structure Development during Continuous Hot-Drawing of Poly(Trimethylene Terephthalate) Fibers by Simultaneous Synchrotron Small- and Wide-Angle X-Ray Scattering. Polymer, 42, 7161-7170. https://doi.org/10.1016/S0032-3861(01)00045-3

[5] Wu, G., Li, H., Wu, Y. and Cuculo, J.A. (2002) Structure and Property Studies of Poly(Trimethylene Terephthalate) High-Speed Melt Spun Fibers. Polymer, 43, 4915-4922.

[6] Ferri, J.M., Fenollar, O., Jorda-Vilaplana, A., García-Sanoguera, D. and Balart, R. (2016) Effect of Miscibility on Mechanical and Thermal Properties of Poly(Lactic Acid)/Polycaprolactone Blends. Polymer International, 65, 453-463.

https://doi.org/10.1002/pi.5079

[7] Mathurosemontri, S., Auwongsuwan, P., Nagai, S. and Hamada, H. (2014) The Effect of Injection Speed on Morphology and Mechanical Properties of Polyoxymethylene/Poly(Lactic Acid) Blends. Energy Procedia, 56, 57-64. https://doi.org/10.1016/j.egypro.2014.07.131

[8] Sheng, C., Wenting, B., Shijian, T. and Yuechuan, W. (2008) Synthesis, Characterization, and Redox and Electrochromic Behaviors of Poly (3-n-Octyloxythiophene). Journal of Applied Polymer Science, 109, 22-25. https://doi.org/10.1002/app.27604

[9] Drumright, B.R.E., Gruber, P.R. and Henton, D.E. (2000) Polylactic Acid Technology. Advanced Materials, 12, 1841-1846. https://doi.org/10.1002/1521-4095(200012)12:23<1841::AID-ADMA1841>3.0.CO;2$\underline{\mathrm{E}}$

[10] Perego, G., Cella, G.D. and Bastioli, C. (2002) Effect of Molecular Weight and Crystallinity on Poly(Lactic Acid) Mechanical Properties. Journal of Applied Polymer Science, 59, 37-43. https://doi.org/10.1002/(SICI)1097-4628(19960103)59:1<37::AID-APP6>3.0.CO;2$\underline{\mathrm{N}}$

[11] Jalali, A., Huneault, M.A. and Elkoun, S. (2017) Effect of Molecular Weight on the Nucleation Efficiency of Poly(Lactic Acid) Crystalline Phases. Journal of Polymer 
Research, 24, 182. https://doi.org/10.1007/s10965-017-1337-x

[12] Li, H. and Huneault, M.A. (2007) Effect of Nucleation and Plasticization on the Crystallization of Poly(Lactic Acid). Polymer, 48, 6855-6866. https://doi.org/10.1016/j.polymer.2007.09.020

[13] Hamada, H. and Tsunasawa, H. (1996) Correlation between Flow Mark and Internal Structure of Thin PC/ABS Blend Injection Moldings. Journal of Applied Polymer Science, 60, 353-362. https://doi.org/10.1002/(SICI)1097-4628(19960418)60:3<353::AID-APP8>3.0.CO;2$\underline{\mathrm{K}}$

[14] Asiri, A.M. (2011) Improved Photochromic and Fatigue Performance of (E)-Dicyclopropylmethylene-(2,5-Dimethyl-3-Furylethylidene)-Succinicanhydride Doped in Polyurethane Thin Film. Polymer Engineering and Science, 25, 1212-1216. https://doi.org/10.1002/pen.22189

[15] Saeidlou, S., Huneault, M.A., Li, H. and Park, C.B. (2012) Poly(Lactic Acid) Crystallization. Progress in Polymer Science, 37, 1657-1677.

https://doi.org/10.1016/j.progpolymsci.2012.07.005

[16] Rybnikár, F., Hoffmann, J. and Mládek, M. (1979) Structure and Morphology of Poly(2,3-Dichlorobutadiene). Polymer, 20, 94-98. https://doi.org/10.1016/0032-3861(79)90050-8

[17] Idumah, C.I., Nwachukwu, A.N. and Akubue, B.N. (2014) Comparative Evaluation of the Effects of Time of Heat Setting and Wet Processing on Shearing Properties of Knitted Ingeo TM Poly (Lactic Acid) (PLA) and Polyethyleneterepthalate Fabric. American Journal of Materials Engineering and Technology, 2, 1-6.

[18] Ma, Y., Yu, L., Jin, S., Zhao, D. and Zhang, S. (2019) Effect of Interfacial Coating and Testing Conditions on the Flexural Performance of Carbon Woven Fibre-Reinforced Polyamide Laminates. Plastics, Rubber and Composites, 48, 57-65. https://doi.org/10.1080/14658011.2018.1547029

[19] Zou, H., Yi, C., Wang, L. and Xu, W. (2010) Crystallization, Hydrolytic Degradation, and Mechanical Properties of Poly (Trimethylene Terephthalate)/Poly(Lactic Acid) Blends. Polymer Bulletin, 64, 471-481. https://doi.org/10.1007/s00289-009-0191-3

[20] Manikandan Nair, K.C., Thomas, S. and Groeninckx, G. (2001) Thermal and Dynamic Mechanical Analysis of Polystyrene Composites Reinforced with Short Sisal Fibres. Composites Science and Technology, 61, 2519-2529. https://doi.org/10.1016/S0266-3538(01)00170-1

[21] Joseph, P.V., Mathew, G., Joseph, K., Groeninckx, G. and Thomas, S. (2003) Dynamic Mechanical Properties of Short Sisal Fibre Reinforced Polypropylene Composites. Composites Part A: Applied Science and Manufacturing, 34, 275-290. https://doi.org/10.1016/S1359-835X(02)00020-9

[22] Bhattacharya, P. and Das, C.K. (2013) In Situ Synthesis and Characterization of $\mathrm{CuFe}_{10} \mathrm{Al}_{2} \mathrm{O}_{19} / \mathrm{MWCNT}$ Nanocomposites for Supercapacitor and Microwave-Absorbing Applications. Industrial and Engineering Chemistry Research, 52, 9594-9606. https://doi.org/10.1021/ie4005783 